0 desastre na escuridão

(Apontamentos para a construção

de uma Poética do Inominável)

"Uma linguagem é uma forma de vida"

(Wittgenstein).

1. A linguagem é pensamento; e o pensamento é o modo como configuramos o mundo. Quando determinados autores focam seu interesse na linguagem, o que eles fazem é atacar - em sua base - o modo como percebemos/construímos o mundo. Ao abordar a linguagem, desconstruíla ou reconstruí-la de maneira inusual (através de arquiteturas linguísticas que propõe habitaçôes distintas da vivência cultural hegemônica: outros modos de subjetivação), é a própria maneira como pensamos (e portanto todo o modo de nos relacionarmos com o mundo) que é afetada. Criam assim - através de uma manipulação formal da linguagem, que para cada autor se dá de modo diferente e com intençóes diferentes -, criam assim POÉTICAS que nos proporcionam novas ferramentas para compreendermos (e até redefinirmos) nossas vidas. Ferramentas que podem nos proporcionar uma RENOVAÇÃO DA NOSSA SENSAÇÃO DE MUNDO. E o único modo de fazê-lo não é através de um discurso - pois se o discurso é expresso de forma reconhecível, se torna tão anódino quanto qualquer comercial de TV.

\section{Roberto Alvim}

Nestes autores (e penso aqui no norte-americano Richard Maxwell, autor das três obras que compõe o TRÍPTICO, encenação mais recente - 2010/2011 - da companhia Club Noir) não há mais dicotomia entre forma e conteúdo: A FORMA DA PEÇA É O SEU CONTEÚDO. O palco se torna não mais um território de ilusão, mas de CONSTRUÇÃO DE POÉTICAS, onde novas realidades são construídas e desconstruídas (haja vista que a própria realidade é um jogo de linguagem com regras específicas), e onde ESSE PROCESSO É APRESENTADOPELOAUTORAOPÚBLICO. (Problema: como atuar nestes textos, se nossos atores vêm quase indistintamente de uma escola figurativa de interpretação? Não se trata aqui da vida como ela $e ́$, mas das coisas como elas realmente são.) $\mathrm{O}$ teatro não trata mais de reproduzir de modo mais ou menos deformado o real, mas se torna uma MEDITAÇÃO SOBRE O REAL. Sobre o modo como percebemos - e CONSTRUÍMOS, PELA LINGUAGEM - o real.

2. Em relação aos atores: evitar, sobretudo, o PLEONASMO entre o que se acredita ser o sentido de uma frase e uma entonação/gestualidade naturalista.

Roberto Alvim é dramaturgo, encenador e professor da SP Escola de Teatro. 
3. Há algumas linhas de força na prolífica obra de Richard Maxwell (mais de 30 textos escritos e encenados até o momento), ou algumas ferramentas, ou algumas estratégias que são usadas pelo autor com alguma recorrência. Entre elas poderia-se apontar: o uso do silêncio, que revela a nudez e o isolamento das subjetividades (ou da enxurrada verbal, que só desencadeia um silêncio mais profundo); o não-dito, a suspensão (lembrando que o não-dito pode ser expresso através do silêncio ou até mesmo das palavras, quando estas obliteram um discurso que as perpassa); o uso de recursos épicos como forma de distanciamento ou, paradoxalmente, de mergulho na subjetividade das personagens (as músicas cantadas pelas personagens em quase todas as suas peças); um rigor absoluto no uso das palavras (que são o tijolo fundamental da construção de sua poética - a PALAVRA, e não a IMAGEM); a ausência quase total de rubricas (o que implica em amplas tomadas de decisão por parte do encenador e dos atores); a permanente ambigüidade a respeito do que é real e do que não é, ou melhor, A PERCEPÇÃO DE QUE O REAL (ASSIM COMO O TEMPO E O ESPAÇO) É SEMPRE UMA CONSTRUÇÃO E NÃO UMA EXPERIÊNCIA AUTOONOMA QUE PARTILHAMOS; e a musicalidade rítmica do texto. Muitas vezes a MÚSICA das palavras chega ao ponto de quase substituir a própria idéia de TRAMA (esteio do drama tradicional)

4. As ferramentas citadas são introduzidas na dramaturgia (algumas apenas insinuadas) por autores como Harold Pinter e Samuel Beckett a partir de meados do século XX. Mas Richard Maxwell não se coloca numa condição de ruptura; ao contrário, se localiza como parte de uma tradição, a qual cabe a ele desdobrar em insuspeitadas veredas. (Recordo-me de Jon Fosse, que se diz ligado inexoravelmente a uma tradição de autores trágicos que remonta à origem grega. Ou de Sarah Kane, que sempre falou de seu amor por Pinter e Brecht e da influência deles sobre ela.) Se não dialogamos com o passado, se não o visitamos, o que nos resta é a mudez (Umberto Eco). É nítido que um autor como Maxwell só escreve o que escreve hoje porque Beckett escreveu o que escreveu durante sua vida; mas percebo também que a obra de Maxwell traz um uso destas ferramentas que é muito pessoal, muito autoral, e que é novo, porque amplia esse uso, abrindo e habitando outro espaço/tempo existencial. Como o norueguês Arne Lygre, que toma estratégias de B. Brecht e faz um uso completamente novo delas - com intenções e resultados absolutamente distintos dos de Brecht. Jon Fosse é uma das vozes mais inovadoras do teatro contemporâneo, e é um autor atrelado à tradição, que usa todas as ferramentas citadas acima, mas de um modo como nenhum outro autor sonhou ou ousou usar. São outros tempos, as respostas dos autores são outras, ainda que algumas conquistas formais do século $\mathrm{XX}$ perdurem no trabalho dos novos dramaturgos - mas de modo ampliado ou deslocado ou radicalizado ou ressignificado, o que nos leva a lugares desconhecidos. Lugares onde nem Beckett nem Brecht nem Pinter nos tinham levado.

5. Criar outros jogos de linguagem - distintos da poética figurativa (isto é, naturalista/realista), que talvez já não tenha muito mais para nos ensinar ou esclarecer sobre as relações humanas. $(\mathrm{O}$ caso é que o jogo figurativo parece gasto, devido à sua vasta apropriação pelos mass media). Uma questão estética é sempre uma questão existencial; neste sentido, a construção de outras poéticas significa a proposição de outras possibilidades de experienciarmos a condição humana.

6. A narrativa, aqui, NÃO É O SENTIDO das peças.

7. O fundamental é entendermos a História da Arte não como um percurso evolutivo (o que sempre redunda em becos sem saída, em esterilidade), mas como uma TRAJETÓRIA DE 
CONSTRUÇÃO DE POÉTICAS, que respondem ao espaço-tempo de cada autor. Uma POÉTICA é um JOGO DE LINGUAGEM. Construir uma poética é estabelecer as REGRAS do jogo - jogo este que, necessariamente, atua no sentido de ampliar a experiência humana, para além da experiência que a instância da cultura nos proporciona.

8. A questão figurativa (poética naturalista/realista) é perigosa porque pretende reinar até sobre o próprio fato-teatro (isto é, sobre o teatro como lugar de construção de jogos de linguagem), impondo a narrativa como sentido único da obra. Para trabalhar com a figura (personagem) num contexto figurativo, é necessário criar uma estrutura rigorosa e limitadora o bastante para promover uma espécie de isolamento (penso nas personagens do pintor Francis Bacon, figurativas mas habitando um espaço que não se estrutura em consonância com elas). É uma força que vem não das personagens, mas de fora, uma força externa, estrutural. É assim que o fato-teatro se impóe, e o figurativo pode ser visitado sem reinar - este, o norte conceitual de TRÍPTICO.

9. A figura assim isolada (do contexto figurativo) torna-se um ÍCONE.

10. Existe uma LÓGICA DA SENSAÇÃO (penso no ensaio de G. Deleuze sobre Francis Bacon) - e é com ela que trabalhamos.

11. Operar a partir de dois pontos terminais (a obra de arte é perpassada pela tensão oriunda da luta permanente entre representar o mundo, ou estabelecer a autonomia da obra):

\section{A DÚVIDA DE CEZANNE \\ (figuração $\mathrm{x}$ abstração)}

A DESCONSTRUÇÃO MINIMAL

(reduzir ao mínimo, como estratégia, os elementos com os quais se trabalha).
12. Ao nada do absurdo,

do desespero,

e também ao nada da incomunicabilidade, contrapor uma outra experiência que o nosso entendimento existencial desconhece.

13. Porque não estamos aqui na esfera da psicologia, ou na esfera dos arquétipos, ou na esfera dos sentimentos nomeáveis

(sínteses de toda e qualquer espécie); estamos trabalhando com a parcela de vivência humana que não tem nome - algo EXTRÍNSECO ao si mesmo cultural.

14. Trabalhar com a produção de diferentes espécies de intensidade, que se sucedem em elipses de tempo/espaço muito mais próximas da lógica da poesia que da lógica da prosa.

15. Aos atores: ao contrário de uma postura afirmativa, encontrar sua presença na ausência, e na ausência sua presença (aparente "simplicidade" (na verdade: REDUÇÃO conquistada) produto de uma abordagem de alta complexidade técnica - vide o trânsito entre diferentes usos da linguagem presentes no NÓ BORROMEANO de J. Lacan, base de nosso trabalho com a voz).

16. Minha relação com os atores é como a de Carlos Zílio com a cor siena - e a deles com a cena é como a de Cy Twombly com a tela (construção de traços, borróes e apagamentos - vide R. Barthes em seu ensaio sobre o pintor).

17. Pensar um sistema dramático estrito a partir de dados fundamentais constitui a verificação e reconstituição dessa cena através daqueles mesmos dados que, no limite, decretaram sua morte (não se trata de pós-dramático, mas da configuração de uma DRAMÁTICA fundada em esteios muito distintos daqueles que pautaram o drama clássico). 
18. Reduzir ao nada ou quase nada é a atitude metodológica de estar na posição de ter a cena toda como um dado externo integral, e objetivada; o oposto do artista moderno que ainda estava dentro da obra e era parte indissociável dela. A cena se torna, de maneira irremediável, algo visto de fora, até, e principalmente, pelo artista contemporâneo (ator e diretor). É ele que deve tentar INCORPORÁ-LA nesse EXÍLIO MÚTUO.

19. A obra nos livra do TRÁGICO, ou seja, de nós mesmos.

20. A cena se dá (em TRÍPTICO) sob a forma de DESLOCAMENTOS, e não mais de OPOSIÇŌES. Trânsitos, em permanente instabilidade, entre diferentes usos da linguagem.

21. Se você segue a natureza, não será de forma alguma capaz de subjugar o trágico em sua arte. Piet Mondrian

22. Não é tão azul quanto pensávamos. Para ser azul não deve haver perguntas.

Wallace Stevens

23. A singularidade é o tema perpétuo da constituição de obras de arte, uma singularidade que está além do alcance humano. Em suma, a cena é um atalho para o inatingível.

\section{A geometria devora a sua metafisica.} Barnett Newman

25. O que instiga o nosso interesse é a angústia de Cezanne - eis a lição de Cezanne.

Pablo Picasso

26. Até que ponto se pode ir dentro de rigorosas limitações auto-impostas? Até que ponto se pode reduzir e, ainda assim, fazer a cena viver (vide os retângulos vivos de Barnett Newman)? Três explicações para estas formas aparentemente perversas (em sua redução quase sadomasoquista):
A. Ao se posicionar contra a "total liberdade" do teatro contemporâneo, opta-se por disciplinar-se, buscando variaçóes (mínimas, mas suficientes) no âmbito de uma linguagem estritamente confinada;

B. Ao cultivar uma obra cuja absurdidade cheira a anti-arte, dá-se margem ao nascimento de uma arte que é, sobretudo, anti-anti-arte;

C. Forçar o receptor a se deter e a se concentrar para ver o que quer que seja na obra. Ao se opôr à atividade aberta-a-tudo do teatro contemporâneo, que funciona como um estimulante para as fantasias do espectador, presenteia-se o público com um artefato espaço-temporal do qual ele nada obterá a não ser que esteja apto para olhar exaustivamente para algo extrínseco a si.

27. O nível de esforço artístico necessário para produzir tal redução...

(Porque não se trata apenas de reduzir, mas de manter a VIDA da FORMA - caso contrário tudo se torna simplório e anódino.)

28. Were all the stars to dissapear or die I should learn to look at an empty sky And feel its total dark sublime.

W. H. Auden

29. Perguntar-se sobre a FORMA DO TEMPO.

30. ARTE COMO ARTE (um teatro de operaçôes - vide a obra de Ad Reinhardt).

31. Como os românticos (que primeiro declararam a independência dos artistas), ver a arte como manifestação essencial da liberdade humana - mas definir essa liberdade como libertação de si e do fluxo do dia-a-dia (isto é, da cultura).

32. A definição de arte como a construção de um complexo sistema de relações formais, criado no mais amplo contexto de construçóes anteriores; isso importa mais que seu significado. 
33. Um trabalho de arte encontra seu lugar na sequência, ao mesmo tempo antes e depois, de outros trabalhos de arte. Todo grande trabalho de arte nos força a rever/reavaliar todos os trabalhos de arte anteriores.

34. A voz constrói PLANOS: avança (para fora do palco); recua (para dentro dele); cria transparências através das quais podemos vislumbrar algum aspecto; bloqueia completamente nosso acesso; estimula nosso imaginário, nos permitindo ver em nosso espaço mental; nos trás de volta para o aqui-agora da sala de espetáculos. A voz: música que cria diferentes planos, produzindo uma espécie de efeito estereofônico (estereofonia que não é apenas sonora, mas que transita por esferas sensoriais, imagéticas, conceituais). Criadora de véus translúcidos e de sólidas barreiras; criadora de texturas e vibraçōes que enchem o espaço de sensaçôes inomináveis; criadora de realidades ostensivamente ficcionais e de fatos-linguagem. Trânsito permanente entre evocação e invocação. Nem nos confina inteiramente à frieza da superfície, e nem recua todo tempo para trás dela, mas escava planos que saem uns de dentro dos outros.

35. A sensação nunca aparece ANTES; ela está inteiramente contida na fala, quando da sua emissão (isto oblitera a abordagem psicológica).

36. Corpo e voz são campos estéticos autônomos um em relação ao outro, entidades não-associadas. É assim que devem ser encarados e trabalhados pelo ator (evitando o pleonasmo: o vetor uni-direcionado, ilustrativo, didático, sublinhado. Deste modo é possível que tudo se mantenha na esfera da sugestão).

37. Conceito de imobilidade-móvel: apesar da aparente imobilidade física dos atores, o movimento entre estes planos vocais - que se dá no tempo e não no espaço - é um dos fundamentos desta Dramática. A originalidade do procedimento é nossa contribuição para a ampliação do working space do teatro.
38. Imóveis no espaço, estamos muito velozes no tempo (vide a Teoria da Relatividade de A. Einstein).

39. As diferenças (mínimas mudanças) ressaltam justamente porque há pouca coisa, tão pouca que cada agora, aqui, isto e aquilo tornase muito.

40. Fazer do mínimo sinal um acontecimento.

41. O teatro é hoje um dos únicos lugares em que podemos tocar o que a razão não alcança completamente. No vazio da cena, no silêncio visível da ausência, algo decanta. Vamos ao teatro para tocar o que decanta no vazio.

42. No contexto de um teatro barulhento e gestual, nós colocamos os receptores face a face com um silêncio paralisado, devastado.

43. O branco, a imobilidade, o silêncio, a inexpressividade, não são provocaçôes, mas uma herança poética que vem, entre outros, de Mallarmé.

44. É preciso que haja sempre uma ambivalência entre ground e motif.

45. Temos que enxergar a parcela de experiência humana (isto é, de vida) que ainda não foi sufocada pela tempestade de imagens e barulho da contemporaneidade. Temos que elaborar uma experiência estética que não ecoe ingenuamente nenhum dos discursos hegemônicos da cultura. Nunca houve tanto som e imagem. TRÍPTICO constrói o silêncio e o vazio. Não o silêncio e o vazio estéreis, anódinos. Construir a forma hodierna do silêncio e do vazio, seu insuspeitável desenho no espaço e no tempo; desenhar linhas de fuga.

Este teatro, embora seja também um contra-fluxo à cultura contemporânea, se sintoniza com a abstração crescente da vida hodierna e, particularmente, da vida urbana. O termo-chave de Anthony Giddens para esta abstração (ou alienação) é desencaixe. 
46. Nada causa mais repulsa e incômodo ao senso comum que o conceito de alteridade. A alteridade instaura outra experiência do humano o que é intolerável (mais do que nunca em nossa era de comunidade global), e dá-se a isto, na falta de outro rótulo (posto que não há, ao menos no surgimento da alteridade), a designação genérica de estranho.

Ser estranho (diferente do senso comum, isto é, elaborado de modo distinto das estratégias de construção empregadas pela cultura de massa) não é um valor em si mesmo. É preciso que esta estranheza advenha da instauração de uma Poética: um sistema complexo de relaçôes formais que, articuladas, promovam uma outra experiência do humano (sempre uma ampliação, haja vista ser uma contra-partida dialética à cultura).

47. Não é a narrativa que queremos mostrar mas a semente da narrativa: o gráfico específico de forças mobilizadas por Richard Maxwell em sua escritura. Para encenarmos sua obra, dialogamos não com a forma final das peças, mas com a pulsão (o sintoma indecifrável) que o levou a escrevê-la. Não procuramos responder à pergunta que o autor formula, mas procuramos, sim, fazer a mesma pergunta.

48. A narrativa é um método de sentido. Como todo método, trás consigo uma ideologia - ao se impôr, impõe também uma determinada imagem do humano. Essa imagem é, desde há muito, hegemônica. Aceitá-la significa aceitar que a vida humana consiste em uma determinada coisa - e é contra esta norma que nosso teatro se coloca.

49. Há uma conjunção entre palavra e tempo que transforma o tempo em espaço.

"O tempo é espaço" (Rainer Maria Rilke).
50. A palavra como rizoma.

$\mathrm{O}$ movimento como rizoma.

O rizoma é uma semente que cresce em várias direções - e cresce no solo preparado do espaço mental de quem vê (observador) e de quem faz ver (ator).

51. Para bordejar o abstrato, paradoxalmente, é preciso ser absolutamente concreto. Tentar tocálo diretamente só leva à fantasia (e por fantasia entenda-se a ilusão do auto-engano).

52. TRÍPTICO promove um deslocamento radical: do eixo interno (situação ficcional) para o eixo externo (emissão de signos para o receptor/ platéia). O ponto central, então, é o da transmissão de signos - rizomáticos, purulentos (no dizer de Artaud), indecidíveis (no dizer de Luiz Fernando Ramos) quanto ao seu significado último; mas poderosos o suficiente para nos instigar a procurarmos por seus significados - ou para inventá-los. E se o ponto é a transmissão, o ator torna-se invisível, desaparece - e esta qualidade de presença é mais autêntica (vide a obra de Alberto Giacometti), porque é mais próxima da Dasein (no emprego de M. Heidegger) e mais distante da máscara (isto é, da cultura, do sujeito cultural). Este procedimento, aliado à escuridão da cena (que oblitera os rostos dos atores), confere às figuras um estatuto ontológico. Abre-se, então, um insuspeitado e infinito campo do humano, explorado pela arte e nunca tocado no âmbito da cultura (que só trabalha com o sujeito estratificado definido na modernidade como único modo de subjetivação possível).

53. O teatro deve ter a chance de tocar o infinito contido nas palavras (operação de desencobrimento do texto, no dizer de M. Heidegger).

No teatro o que importa não é dizer (bem ou mal) o texto, mas trabalhar para que o texto faça ver, para que as palavras nos transportem, nos desloquem, instaurem uma qualidade de experiência da ordem do enigma. 
54. TRÍPTICO existe em uma interzona: um espaço/tempo em comunicação com zonas conhecidas, mas que é fundamentalmente uma seara desconhecida.

55. A luz é, ao mesmo tempo, presente e impalpável. (Neste sentido, sua especificidade coloca-se como paradigma para a atuação matéria e imaterialidade conjugadas.)

Em TRÍPTICO foi criada uma dramaturgia da luz, através de três operações fundamentais:

A. Transubstanciação do lugar comum, pelo uso insuspeitado das lâmpadas flúor. Estas lâmpadas, de fabricação industrial, compradas em qualquer loja, são o símbolo máximo de nossa sociedade anódina e impessoal, mas aqui são usadas de modo a afetar a percepção dos receptores (e dos atores), instaurando estranhas atmosferas que remetem a (mas deformam sensivelmente) seu uso cotidiano;

B. Escuridão, penumbra quase permanente, que confere dimensão ontológica às figuras no palco (instância abstrata), privando-nos de enxergar seus rostos, e nos permitindo assim projetar uma série de conteúdos inconscientes sobre as personagens, instaurando um perpétuo estado de incerteza;

C. Focos muito fechados, que iluminam apenas os rostos dos atores, e que se alternam abruptamente com a escuridão penumbrosa das silhuetas, alterando a percepção (nosso olhar tem dificuldade de focar por conta destes trânsitos violentos), conferindo às figuras, momentaneamente, a condição de sujeitos (instância figurativa).

\section{O dark dark dark}

"They all go into the dark" (T.S. Eliot)

"It is dark disaster.

That brings the light" (Blanchot).
57. É no sacrifício destruidor da boa articulação que vemos surgir a forma contemporânea da beleza. Uma estranha beleza, que não se constitui pelos valores estéticos hegemônicos, mas que encontra-se na elegância com a qual uma determinada realidade se presentifica, forçando a nossa visão e, assim, tornando-se novamente digna de nossa atenção.

58. E se não há pathos, algo emerge de mais potente: a própria linguagem.

59. A palavra significa por diferença.

A imagem significa por semelhança.

Quando evitamos qualquer procedimento cultural (mesmo no campo da gestualidade, por exemplo, ou da ordenação estrutural da obra), é por que queremos permanecer no terreno da diferença em relação ao mundo - recusando a apresentação de modos de cultura no palco e fazendo da experiência estética uma experiência poética, no sentido da transubstanciação dos sentidos e da revolução dos signos. Vem daí a dificuldade de diálogo que a obra estabelece com percepções acostumadas à facilidade das imagens ilustrativas.

60. Quando Barnett Newman traça sua linha (zip) no plano, está mais próximo da palavra que da imagem: significa por diferença, não por semelhança. Aí sua arte se aproxima mais da literatura - e, na literatura, da poesia (sua epifania) - do que de uma produção de imagens.

A imagem pertence ao espaço. A poesia pertence ao tempo.

61. TRÍPTICO é um teatro que dialoga com a poesia (em sua supremacia do significante e em sua enunciação do significado como um torvelinho labiríntico, assim como em sua instável construção elíptica do tempo, do espaço e do sujeito - penso em F. Holderlin e em Robert Crewley).

O prazer ligado à poesia é resultado da destruição e dissolução que ela causa ao sentido cultural das palavras. 
62. É na linguagem, diz M. Heidegger, que se cumpre a relação humana com o ser/estar, isto é, na linguagem se cumpre nossa Ek-sistenz. Para Heidegger, o modo de ser especificamente humano é sua Ek-sistenz, que sua perspectiva ontológica define não como um mero fato de existir, mas como nossa essencial relação com o ser/ estar. Na linguagem, portanto, realiza-se/inventa-se o homem. Linguagem não é apenas mero instrumento de comunicação, mas o estabelecimento específico de nosso estar no mundo, desta ou daquela ou de infinitas outras maneiras.

63. É a distinção entre o peso pré-fabricado da história e a experiência direta que evoca em mim a necessidade de fazer coisas que nunca antes foram feitas (Richard Serra).

64. Artistas com quem nos mantemos em permanente conversação:

Willem de Kooning - deslocamentos entre planos pictóricos, tensão entre abstração e figuração;

Mark Rothko - sensações crepusculares (arte ontológica);

Barnett Newman - trabalhar no campo do inominável (operar como o Gênesis bíblico);

Ad Reinhardt - arte como algo extrínseco ao si mesmo cultural;

Cy Twombly - intensa ambivalência entre todos o elementos da obra (a originalidade consiste em um agudo discernimento do quão pouco um artista pode ousar fazer no decorrer da criação de uma obra de arte).

65. Ora, onde mora o perigo

"É lá que também cresce.

O que salva" (F. Holderlin).
66. EU FALO: EU EXISTO. (A célebre fórmula de Lacan. É o modo como eu falo que define o modo como eu existo. Cada arquitetura linguística define um modo de habitarmos o mundo.)

67. O espaço está vazio para que possa estar pleno de linguagem.

68. A grande ação realizada em TRÍPTICO é a fala: é ela que constrói e desconstrói o espaço; que promove transportes instáveis no tempo; que evoca e invoca; é através da fala, na fala, que a presença humana habita distintos modos de subjetivação. E é em todas as problemáticas ligadas a este ato (que não se relaciona com $e x-$ pressão, mas sim com invenção) que a obra se situa, se desdobra, se expande - em direções sempre impossíveis.

69. Não se trata, nesta obra, de entendimento (compreensão univoca da narrativa, objetificação do sujeito e esclarecimento acerca de suas motivaçôes), mas sim de produção e experienciação de intensidades desestabilizadoras. Produção de intensidades: produção de diferentes espécies de intensidade; em termos de estratégia de construção cênica, a produção de intensidades é o avesso do sistema acumulativo de Hegel: trata-se, aqui, da construção e apagamento imprevisíveis de linhas de fuga; isso altera profundamente nossa percepção do tempo.

70. Richard Maxwell é o criador de uma Poética fundante, de um teatro que não se configura como ESPELHO DO MUNDO, mas que se instaura como insuspeitada TECELAGEM: rede de fios engendrados por outros modos de subjetivação, por afetos e sensaçôes e imagens e construçốes que são da ordem do INOMINÁVEL posto que se localizam fora da cartografia reconhecível da cultura. Não nos reconheceremos nem a nós, nem ao nosso mundo - nestas obras; o que veremos aqui são outras possibilidades, ligadas ao fim da ideia moderna de sujeito, e ao surgimento de uma outra lógica de funcionamento para a humanidade em nossos dias. 